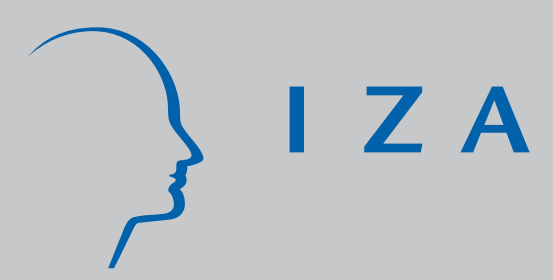

IZA DP No. 5881

On Input Market Frictions and Estimation of Factors Demand

Arnaud Dupuy

Todd Sorensen

July 2011

Forschungsinstitut zur Zukunft der Arbeit Institute for the Study of Labor 


\title{
On Input Market Frictions and Estimation of Factors Demand
}

\author{
Arnaud Dupuy \\ ROA, Maastricht University \\ and IZA
}

Todd Sorensen

University of California, Riverside

and IZA

Discussion Paper No. 5881

July 2011

IZA

P.O. Box 7240

53072 Bonn

Germany

Phone: +49-228-3894-0

Fax: +49-228-3894-180

E-mail: iza@iza.org

Any opinions expressed here are those of the author(s) and not those of IZA. Research published in this series may include views on policy, but the institute itself takes no institutional policy positions.

The Institute for the Study of Labor (IZA) in Bonn is a local and virtual international research center and a place of communication between science, politics and business. IZA is an independent nonprofit organization supported by Deutsche Post Foundation. The center is associated with the University of Bonn and offers a stimulating research environment through its international network, workshops and conferences, data service, project support, research visits and doctoral program. IZA engages in (i) original and internationally competitive research in all fields of labor economics, (ii) development of policy concepts, and (iii) dissemination of research results and concepts to the interested public.

IZA Discussion Papers often represent preliminary work and are circulated to encourage discussion. Citation of such a paper should account for its provisional character. A revised version may be available directly from the author. 
IZA Discussion Paper No. 5881

July 2011

\begin{abstract}

\section{On Input Market Frictions and Estimation of Factors Demand ${ }^{*}$}

In this paper we explore the impact of imperfectly competitive input markets on production function estimation. First order profit maximizing conditions are altered when frictions in input markets cause the elasticity of input supply to the firm to be finite. A consequence of this is that the standard econometric model used for production function estimation will be misspecified. We prove that, in all non trivial cases, finite elasticities of supply to the firm will lead to inconsistent estimates of production function parameters. Monte Carlo simulations show that the resulting bias can be economically significant.
\end{abstract}

JEL Classification: D2, J42, J23

Keywords: input market frictions, labor market frictions, estimation of factor demand

Corresponding author:

Todd Sorensen

Department of Economics

University of California, Riverside

4128 Sproul Hall

Riverside, CA 92521

USA

E-mail: todd.sorensen@ucr.edu

\footnotetext{
* We thank Arindrajit Dube and Torberg Falch and seminar participants at the Norwegian University of Science and Technology for useful comments. Todd Sorensen is grateful to ROA Maastricht University where part of this research was conducted during a sabbatical visit.
} 


\section{Introduction}

The last fifteen years have seen a dramatic increase in the literature on labor market imperfections. Work by Burdett and Mortensen (1998) has established the role of search costs in creating labor market frictions. Manning (2003) shows how, even in the presence of many competing firms in the labor market, these frictions imply that a monopsony model may best represent the functioning of the labor market. Recent empirical tests have supported these works by uniformly rejecting the hypothesis of perfectly elastic labor supply to the firm ${ }^{1}$.

Separately, many great contributions to our understanding of labor markets have come through empirical estimates of production function parameters. Studies on skill biased technological change and changes in relative wages include Katz and Murphy (1992), Acemoglu (1999;2002), and Card and Lemieux (2003). Structural work on the impact of immigration on the wages of natives include Borjas (2003), Card (2009) and Ottaviano and Peri (2011). In their analyses, these studies use the standard assumption of perfectly competitive labor markets to arrive at their econometric equation derived from profit maximizing conditions.

Here, we show the consequences of labor market imperfections on the estimation of production functions. Our main finding is that data from an economy with labor market imperfections and a given technology will be rationalized by a different technology under the assumption of competitive labor markets. Specifically, we prove that as long as the elasticities of supply to the firm are finite and not equal to one another, estimates of the production function will not be consistent. To the best of our knowledge, no prior work has addressed this misspecification in the context of labor market frictions. The only work that we are aware of that raises a similar issue is Oaxaca and Lup-Tik (2004), who note that differences in wages between two groups that are not attributable to differences in productivity may bias a nested CES estimation. They use the unexplained portion of the wage gap from a Oaxaca decomposition in a control function approach.

Simulating the estimation of the parameters of a CES production function, we show that constant and unequal elastiticies of supply lead to biased estimates of the efficiency parameters. Elasticities that are a function of the wage lead to biased estimates of the elasticity of substitution between two factors. We find that under reasonable assumptions the bias can be significant enough that a true elasticity of substitution between high and low skilled labor of 2 can be incorrectly estimated as 1.4.

\footnotetext{
${ }^{1}$ Studies measuring these parameters include Ransom and Oaxaca (2005, 2010), Ransom and Simms (2009), Falch (2010), Hotchkiss and Quispe (2009), Hirsch et al (2010) and Depew and Sorensen (2011).
} 


\section{Model}

\subsection{A generic non identification result}

Suppose that the aggregate output of an economy is given as $Y^{t}=F\left(L_{1}^{t}, L_{2}^{t}\right)$ where $L_{1}^{t}$ and $L_{2}^{t}$ are factors of production of respective price $w_{j}\left(L_{j}^{t}\right)$ for $j=1,2$ and the production function $F$ captures technology in use. ${ }^{2}$ Data from this economy is superscripted by $t$ representing an observational unit. ${ }^{3}$ For the sake of simplicity, we assume that the product market is perfectly competitive and use output price as a numeraire to factor prices. In contrast, the markets for factors of production may not be perfectly competitive. To formally capture departures from perfect competition, we define upward sloping supply functions linking factor prices to factors quantities, i.e. $w_{j}\left(L_{j}^{t}\right)$ with $\frac{\partial w_{j}\left(L_{j}^{t}\right)}{\partial L_{j}} \geq 0$. Note that the inverse elasticity of supply of factor $j$, i.e. $\frac{1}{\varepsilon_{j}\left(L_{j}^{t}\right)}=\frac{\partial \ln w_{j}\left(L_{j}^{t}\right)}{\partial \ln L_{j}} \geq 0$, is equal to 0 when $\frac{\partial w_{j}\left(L_{j}^{t}\right)}{\partial L_{j}}=0$. In this case, factor market $j$ is said to be perfectly competitive. Given this setting, we define an economy as a tuple $\left\{\frac{1}{\varepsilon_{1}(.)}, \frac{1}{\varepsilon_{2}(.)}, F(.,).\right\}$. The firms' (static) problem is to choose $\left(L_{1}^{t}, L_{2}^{t}\right)$ to maximize profits $F\left(L_{1}^{t}, L_{2}^{t}\right)-w_{1}\left(L_{1}^{t}\right) L_{1}^{t}-w_{2}\left(L_{2}^{t}\right) L_{2}^{t}$. The FOCs to this problem are:

$$
w_{j}\left(L_{j}^{t}\right)\left(1+\frac{1}{\varepsilon_{j}\left(L_{j}^{t}\right)}\right)=\frac{\partial F\left(L_{1}^{t}, L_{2}^{t}\right)}{\partial L_{j}} \text { for } j=1,2
$$

Taking logs and subtracting the two FOCs obtains:

$$
\ln \frac{w_{1}\left(L_{1}^{t}\right)}{w_{2}\left(L_{2}^{t}\right)}=\ln \frac{\partial \widetilde{F}\left(L_{1}^{t}, L_{2}^{t}\right)}{\partial L_{1}}-\ln \frac{\partial \widetilde{F}\left(L_{1}^{t}, L_{2}^{t}\right)}{\partial L_{2}}
$$

where $\frac{\partial \widetilde{F}\left(L_{1}^{t}, L_{2}^{t}\right)}{\partial L_{j}} \equiv \frac{\frac{\partial F\left(L_{1}^{t}, L_{2}^{t}\right)}{\partial L_{j}}}{1+\frac{1}{\varepsilon_{j}\left(L_{j}\right)}}$. Each economy $t$ generates the tuple $\left\{w_{1}^{t} / w_{2}^{t}, L_{1}^{t}, L_{2}^{t}\right\}$

as data that consists of the ratio of the two factor prices $w_{j}^{t}\left(=w_{j}\left(L_{j}^{t}\right)\right)$ for $j=1,2$ and two factor quantities $L_{j}^{t}$ for $j=1,2$. Equation 2 is the fundamental equation of this paper. Using this equation, one can easily prove the following (non) identification theorem.

Theorem 1 To each economy $\left\{\frac{1}{\varepsilon_{1}(.)}, \frac{1}{\varepsilon_{2}(.)}, F^{a}(.,).\right\}$ corresponds an economy $\left\{0,0, F^{b}(.,).\right\}$, where $F^{b}$ is defined such that $\frac{\partial F^{b}\left(L_{1}^{t}, L_{2}^{t}\right)}{\partial L_{j}}=\frac{\partial \widetilde{F}^{a}\left(L_{1}^{t}, L_{2}^{t}\right)}{\partial L_{j}} \equiv \frac{\frac{\partial F^{a}\left(L_{1}^{t}, L_{2}^{t}\right)}{\partial L_{j}}}{1+\frac{1}{\bar{g}_{j}\left(L_{j}\right)}}$, that both generate the same data $\left\{w_{1}^{t} / w_{2}^{t}, L_{1}^{t}, L_{2}^{t}\right\}$.

\footnotetext{
${ }^{2}$ We abstract from technological change by assuming that $F$ is constant over observational units. This assumption is without loss of generality with respect to our key point. Similarily, we assume that the shape of the supply to the firm of factors of production is constant over time without loss of generality and for the sake of notational simplicity.

${ }^{3}$ Superscript $t$ may represent time, space or variation between other cross-sectional units such as cohorts.
} 
Proof. Let $\left\{w_{1}^{t} / w_{2}^{t}, L_{1}^{t}, L_{2}^{t}\right\}$ be the data generated by the economy $\left\{\frac{1}{\varepsilon_{1}(.)}, \frac{1}{\varepsilon_{2}(.)}, F^{a}(.,).\right\}$. One directly sees that there always exists an economy $\left\{0,0, F^{b}(.,).\right\}$ with $\frac{\partial F^{b}\left(L_{1}^{t}, L_{2}^{t}\right)}{\partial L_{j}}=$ $\frac{\partial \widetilde{F}^{a}\left(L_{1}^{t}, L_{2}^{t}\right)}{\partial L_{j}}$ such that from Equation 2 at factors quantities $L_{1}^{t}$ and $L_{2}^{t}$, this economy produces relative prices equal to $w_{1}^{t} / w_{2}^{t}$. The two economies produce the same data $\left\{w_{1}^{t} / w_{2}^{t}, L_{1}^{t}, L_{2}^{t}\right\}$.

Theorem 1 implies that the function of production $F(.,$.$) , without any ad-$ ditional information about supply elasticities (with the data in hand), is not identified non-parametrically. This non identification result has implications for the estimation of the shape of the production function as stated in the following corollary of Theorem 1 .

Corollary 2 Estimates of $\frac{\partial F}{\partial L_{j}}$ using Equation 2 and data $\left\{w_{1}^{t} / w_{2}^{t}, L_{1}^{t}, L_{2}^{t}\right\}_{t=0}^{T}$ are inconsistent when the two factors have different elasticities of supply, i.e. $\varepsilon_{1}(.) \neq \varepsilon_{2}($.$) .$

Proof. Let the true economy be $\left\{\frac{1}{\varepsilon_{1}(.)}, \frac{1}{\varepsilon_{2}(.)}, F^{a}(.,).\right\}$. The associated generated data are $\left\{w_{1}^{t} / w_{2}^{t}, L_{1}^{t}, L_{2}^{t}\right\}_{t=0}^{T}$, i.e. a sample of $T$ observations of this economy. ${ }^{4}$ Assuming the type of production is known but the parameters not, using these data one estimates $\ln \frac{\partial \widetilde{F}\left(L_{1}, L_{2}\right)}{\partial L_{1}}-\ln \frac{\partial \widetilde{F}\left(L_{1}, L_{2}\right)}{\partial L_{2}}=\ln \frac{\partial F\left(L_{1}, L_{2}\right)}{\partial L_{1}}-$ $\ln \frac{\partial F\left(L_{1}, L_{2}\right)}{\partial L_{2}}+\ln \left(\frac{1+\frac{1}{\varepsilon_{2}\left(L_{2}\right)}}{1+\frac{1}{\varepsilon_{1}\left(L_{1}\right)}}\right)$. The last term only collaspes when $\varepsilon_{2}\left(L_{2}\right)=$ $\varepsilon_{1}\left(L_{1}\right)$, a special case of which is met when both factor markets are perfectly competitive. The sign of the bias in the ratio of marginal productivity will be given by the sign of $\ln \left(\frac{1+\frac{1}{\varepsilon_{2}\left(L_{2}\right)}}{1+\frac{1}{\varepsilon_{1}\left(L_{1}\right)}}\right)$.

\subsection{CES production functions}

Let technology be summarized by a CES production function, i.e. $F\left(L_{1}, L_{2}\right)=$ $\left[\lambda L_{1}^{\rho}+(1-\lambda) L_{2}^{\rho}\right]^{1 / \rho}$ with $\rho \in(-\infty, 1]$. The parameter $\lambda$ measures the efficiency of factor 1 relative to factor 2 whereas the parameter $\rho$ determines $\sigma$ the elasticity of substitution between factors, i.e. $\sigma=\frac{1}{1-\rho}$. Given the CES technology, Equation 2 reads as:

$$
\ln \frac{w_{1}\left(L_{1}^{t}\right)}{w_{2}\left(L_{2}^{t}\right)}=\ln \frac{\lambda}{1-\lambda}+(\rho-1) \ln \frac{L_{1}}{L_{2}}-\ln \left(\frac{1+\frac{1}{\varepsilon_{1}\left(L_{1}\right)}}{1+\frac{1}{\varepsilon_{2}\left(L_{2}\right)}}\right)
$$

It is clear that as long as the last term does not collapse, an estimate $\hat{\lambda}$ of $\lambda$ will

\footnotetext{
${ }^{4}$ The data may vary across observational units for various reasons. An interesting interpretation would be that the wage curves $w_{1}^{t}\left(L_{1}^{t}\right) / w_{2}^{t}\left(L_{2}^{t}\right)$ differ by a scalar factor across units, i.e. $w_{1}^{t}\left(L_{1}^{t}\right) / w_{2}^{t}\left(L_{2}^{t}\right)=\mu^{t} w_{1}\left(L_{1}^{t}\right) / w_{2}\left(L_{2}^{t}\right)$. The equilibrium data are then different across observational units but the elasticities of supply remain similar. Putting $\ln \mu^{t}$ on the right hand side of Equation 2 produces an "error" term that is generally added to the equation in empirical applications.
} 
be biased (upward or downward). It is also clear that as soon as the elasticities in the last term vary with $L_{j}^{t}$, and hence $\ln L_{j}^{t}$, an estimate $\widehat{\rho}$ of $\rho$ will be biased (again upward or downward). Two particularly interesting cases arise.

Case 1: factors have constant supply elasticities, i.e. $\varepsilon_{j}\left(L_{j}\right)=\varepsilon_{j}$. In this case,

Equation 3 becomes:

$$
\ln \frac{w_{1}\left(L_{1}^{t}\right)}{w_{2}\left(L_{2}^{t}\right)}=\ln \frac{\widehat{\lambda}}{1-\widehat{\lambda}}+(\rho-1) \ln \frac{L_{1}}{L_{2}}
$$

where $\ln \frac{\widehat{\lambda}}{1-\widehat{\lambda}}=\ln \frac{\lambda}{1-\lambda}-\ln \left(\frac{1+\frac{1}{\varepsilon_{1}}}{1+\frac{1}{\varepsilon_{2}}}\right)$. The estimate $\widehat{\lambda}$ of $\lambda$ will suffer an upward bias when $\frac{\varepsilon_{2}}{\varepsilon_{1}}<1$ and a downward bias otherwise. However, the estimate $\widehat{\rho}$ will be consistent in this case.

Case 2: supply elasticities are such that $1+\frac{1}{\varepsilon_{j}\left(L_{j}\right)}=\alpha_{j} L_{j}^{\beta}$, with $\beta \in \mathbb{R}$ and $\alpha_{j}>\frac{1}{L_{j}^{\beta}}>0 .^{5}$ In this case, Equation 3 becomes:

$$
\ln \frac{w_{1}\left(L_{1}^{t}\right)}{w_{2}\left(L_{2}^{t}\right)}=\ln \frac{\widehat{\lambda}}{1-\widehat{\lambda}}+(\widehat{\rho}-1) \ln \frac{L_{1}}{L_{2}}
$$

where $\ln \frac{\widehat{\lambda}}{1-\hat{\lambda}}=\ln \frac{\lambda}{1-\lambda}-\ln \left(\frac{\alpha_{1}}{\alpha_{2}}\right)$ and $\widehat{\rho}=\rho-\beta$. Case 1 is clearly a special case met when $\beta=0$ and where $\alpha_{j}=1+\frac{1}{\varepsilon_{j}}$. The bias in the estimate $\hat{\lambda}$ of $\lambda$ is therefore similar to that discussed in Case 1 . In contrast to Case 1 though, as soon as $\beta \neq 0$, an estimate $\widehat{\rho}$ of $\rho$ will suffer a bias: downward bias when $\beta>0$ and upward when $\beta<0$.

Theorem 1 is illustrated in Figure 1 using the specification of Case 2. The marginal costs and marginal productivity of factor 1 relative to factor 2 are plotted on two panels. The left panel corresponds to an economy $\{0,0, \widetilde{F}(.,)$.$\} ,$ i.e. $\beta=0, \alpha_{j}=1$, whereas in the right panel corresponds to an economy $\left\{\frac{1}{\varepsilon_{1}(.)}, \frac{1}{\varepsilon_{2}(.)}, F(.,).\right\} .6$ On each panel, the equilibrium condition captured in Equation 2 corresponds to the crossing point of the marginal cost curves with the marginal productivity curve. In each panel we consider three supply curves capturing shifts in relative supply over time or across countries. The observed

\footnotetext{
${ }^{5}$ Note that solving for the supply function $\ln w_{j}\left(L_{j}\right)$ given our definition $1+\frac{1}{\varepsilon_{j}\left(L_{j}\right)}=$ $\alpha_{j} L_{j}^{\beta}$ yields: $\ln w_{j}\left(L_{j}\right)=\frac{\alpha_{j}}{\beta} L_{j}^{\beta}-\ln L_{j}+$ const $_{j}$ where const $_{j}$ is a constant of integration. Re-write $\frac{\alpha_{j}}{\beta} L_{j}^{\beta}$ as $\alpha_{j}\left(\frac{L_{j}^{\beta}-1}{\beta}+\frac{1}{\beta}\right)$ and note that $\lim _{\beta \rightarrow 0} \frac{L_{j}^{\beta}-1}{\beta} \rightarrow \ln L_{j}$ (see the Box-Cox transformation). Let const ${ }_{j}=w_{j}-\frac{1}{\beta}, \alpha_{j}=1$ and $\beta \rightarrow 0$. We then have $\ln w_{j}\left(L_{j}\right) \rightarrow w_{j}$ which corresponds to the perfect competition case.

${ }^{6}$ In these simulations, we used a CES production function and the parametric shape discussed in section to calibrate the supply curves.
} 
data are represented by the three blue points $\left(\frac{L_{1}^{t}}{L_{2}^{t}}, \frac{w_{1}^{t}}{w_{2}^{t}}\right)$. As stated in Theorem 1 these points are identical in both panels. Note that, in contrast to perfect competition (the left panel), under monopsony (the right panel) these data do not trace out a demand curve consistent with the true production function.

\section{Monte Carlo Simulation}

The simulation exercise considers an economy with CES technology $F\left(L_{1}, L_{2}\right)=$ $\left[\lambda L_{1}^{\rho}+(1-\lambda) L_{2}^{\rho}\right]^{1 / \rho}$ and supply functions as in Case 2 above, i.e. $\frac{1}{\varepsilon_{j}\left(L_{j}\right)}=$ $\alpha_{j} L_{j}^{\beta}-1$. This economy generates data $\left\{w_{1}^{t} / w_{2}^{t}, L_{1}^{t}, L_{2}^{t}\right\}_{t=0}^{N}$. The data generating process is then:

$$
\ln \frac{w_{1}^{t}}{w_{2}^{t}}=\ln \frac{\widehat{\lambda}}{1-\widehat{\lambda}}+(\widehat{\rho}-1) \ln \frac{L_{1}^{t}}{L_{2}^{t}}+u^{t}
$$

where $\ln \frac{\widehat{\lambda}}{1-\widehat{\lambda}}=\ln \frac{\lambda}{1-\lambda}-\ln \left(\frac{\alpha_{1}}{\alpha_{2}}\right)$ and $\widehat{\rho}=\rho-\beta$. The random term $u^{t}$ is independently distributed and follows a Normal distribution ${ }^{7} N\left(0,0.2^{2}\right)$ whose variance is scaled such that the $R^{2}$ of our regressions is about 0.85 . Factor quantities $L_{j}^{t}$ are independently and uniformly distributed over [5, 15].

We consider four economies that share the same technology with elasticity of substitution equal to 2, i.e. $\rho=0.5$, and equal efficiencies for both factors. $\lambda=0.5$. However, these four economies face different factor market structures. In particular:

- $\left(\right.$ Economy 1) $\alpha_{1}=0.3, \alpha_{2}=0.1$ and $\beta=\frac{1}{4}$,

- $\left(\right.$ Economy 2) $\alpha_{1}=\alpha_{2}=0.3$, and $\beta=\frac{1}{4}$,

- $\left(\right.$ Economy 3) $\alpha_{1}=1.5, \alpha_{2}=2, \beta=0$ and,

- $\left(\right.$ Economy 4) $\alpha_{1}=\alpha_{2}=1$ and, $\beta=0$.

Economy 1 corresponds to our benchmark economy with supply elasticities of 2.14 and 1.22 for factor 1 and 2 respectively. Economy 4 is the polar economy that faces perfectly competitive factor markets. Two intermediate cases are also examined. In economy 2, factor markets are imperfect but the elasticities of supply are equal for both factors. In economy 3, the elasticities of supply are constant though different for the two factors. For each economy, we generate 1,000 samples of size $N=100$. For each sample we estimate the parameters $\widehat{l}=\ln \frac{\widehat{\lambda}}{1-\widehat{\lambda}}$ and $\widehat{\sigma}=\frac{1}{1-\widehat{\rho}}$ of Equation 6 using Ordinary Least Square technique. The simulation results are reported in Table 1 . As expected, the estimates of both $\widehat{l}$ and $\widehat{\rho}$ are biased in Economy 1 . The relative efficiency of factor 2 is over estimated and the magnitude of the bias is equal to $\ln \left(\frac{0.3}{0.1}\right)=1.10$. The estimate of the elasticity of substitution is also biased, i.e. $\widehat{\sigma}=\frac{1}{1-\widehat{\rho}}=\frac{4}{3} \approx 1.33$.

\footnotetext{
${ }^{7}$ An interpretation of $u$ is provided in footnote 4.
} 
It is striking to see that given our parametric setting, at feasible magnitudes of supply elasticities ${ }^{8}$, one estimates the elasticity of substitution to be 1.33 (as Katz and Murphy for instance) whereas the true elasticity is equal to 2.

Finally, as expected, estimates of the relative efficiencies are biased in Economy 3 but unbiased in Economy 2 while estimates of the elasticity of substitution are unbiased in Economy 3 but biased in Economy 2.

\section{Conclusion}

Recent work has established strong evidence that the labor elasticity of supply to the firm is finite. Production function estimation based on a representative firm model had typically assumed that the firm faces perfectly competitive input markets. Finite elasticities imply that the firm faces profit maximizing conditions that differ from the standard model. Here, we have explored the economic consequences of this assumption being violated.

Our first finding is that equilibrium data on input factors (wages and quantities) and an incorrect assumption of perfectly elastic labor supply to the firm will be rationalized only with a production function that differs from the true production function in the economy. This is demonstrated in a clear example shown in Figure 1.

We then explore this finding in the context of a CES production function. Elasticities that vary with the wage will generate biased estimates of the elasticity of substitution as well as the efficiency parameters. Even constant but unequal elasticities will bias estimates of the efficiency parameters, though not the elasticity of substitution. It should be noted that, in the context of a NestedCES, incorrectly estimating the efficient parameters in the bottom level of the nest may cause higher level elasticities of substitution to be inconsistently estimated. A Monte Carlo simulation shows that, under reasonable parameter values, the bias in the elasticity of substitution between two groups, say high and low skilled labor, may be significant. Specifically, we show that a true elasticity of 2 may be estimated as 1.4.

These findings provide a caveat for production function estimation. Ideally, a structural model would use data that would also allow for estimation of the labor elasticity of supply to the firm in order to correctly specify the production function estimation model. ${ }^{9}$ However, such firm level data is hard to come by.

A potentially valuable method for applied researchers to follow is the control function approached used by Lup-Tick and Oaxaca (2004) in their paper on gender biased technological change, where they consider that male and female wages may differ for reasons other than differences in marginal productivity,

\footnotetext{
${ }^{8}$ This numbers are comparable with estimates from the studies listed in Footnote 1

${ }^{9}$ Dupuy and Marey (2008) estimate Equation 5 for skilled and unskilled labor in the US between 1963 and 2005. They find that $\widehat{\sigma}=\frac{1}{1-\widehat{\rho}}$ shifts twice over time. Although Dupuy and Marey (2008) argue in favor of technical change as an explanation thereof, Corollary 2 indicates that changes in the relative supply elasticities of skilled and unskilled labor could have generated these shifts.
} 
such as taste based discrimination. In a more general context, their approach of controlling for the unexplained wage gaps from a Oaxaca decomposition may also help tackle the issues raised here, where different labor elasticities of supply to the firm affect wages along with differing marginal productivity. 


\section{References}

Acemoglu, D. (1999): "Changes in Unemployment and Wage Inequality: An Alternative Theory and Some Evidence," American Economic Review, 89(5), $1259-1278$.

- (2002): "Technical Change, Inequality and the Labor Market," Journal of Economic Literature, 40(1), 7-72.

BorJas, G. J. (2003): "The Labor Demand Curve Is Downward Sloping: Reexamining the Impact of Immigration on the Labor Market," The Quarterly Journal of Economics, 118(4), pp. 1335-1374.

Burdett, K., and D. T. Morensen (1998): "Wage Differentials, Employer Size, and Unemployment," Intenational Economic Review, 39(3), 257-273.

CARD, D. (2009): "Immigration and Inequality," American Economic Review, $99(2)$.

Card, D., and T. Lemieux (2001): "Can Falling Supply Explain the Rising Return to College for Younger Men? A Cohort-Based Analysis," The Quarterly Journal of Economics, 116(2), 705-746.

Depew, B., And T. Sorensen (2011): "Monopsony Power and the Business Cycle: Prewar evidence from the Ford Motor Company," Working Paper.

Dupuy, A., and P. Marey (2009): "Shifts and Twists in the Relative Productivity of Skilled Labor," Journal of Macroeconomics, 30, 718-735.

FALCH, T. (2010): "The elasticity of labor supply at the establishment level," Journal of Labor Economics, 28(2).

Hirsch, B., T. Shank, and C. Schnabel (2010): "Differences in Labor Supply to Monopsonistic Firms and the Gender Pay Gap: An Empirical Analysis Using Linked Employer-Employee Data from Germany," Journal of Labor Economics, 28(2), 291-330.

Hotchiss, J. L., and M. Quispe-Agnoli (2009): "Employer Monopsony Power in the Labor Market for Undocumented Workers," Federal Reserve Bank of Atlanta Working Paper, 14a.

Katz, L., and K. Murphy (1992): "Changes in Relative Wages, 1963-1987: Supply and Demand Factors," Quarterly Journal of Economics, 107(1), 3578.

Lup-Tick, S., and R. L. OAxaca (2004): "Technological Change and Gender Wage Differentials," Working Paper.

Manning, A. (2003): Monopsony in Motion: Imperfect Competition in Labor Markets. Princeton University Press, Priceton, N.J. 
OAXCACA, R. (1973): "Male-Female Wage Differentials in Urban Labor Markets," International Economic Review, 14(3), 693-709.

Ottaviano, G. I., and G. Peri (Forthcoming): "Rethinking The Effects of Immigration on Wages," Journal of the European Economic Association.

Ransom, M. R., and R. L. Oaxaca (2005): "Sex Differences in Pay in a "New Monopsony" Model of the Labor Market," IZA Working Paper, 1870.

(2010): "New Market Power Models and Sex Differences in Pay," Journal of Labor Economics, 28(2), 267-290.

Ransom, M. R., and D. P. Sims (2009): "Estimating the Firm's Labor Supply Curve in a âĂIJNew MonopsonyâĂİ Framework: School Teachers in Missouri," IZA Discussion Papers 4271, Institute for the Study of Labor (IZA). 

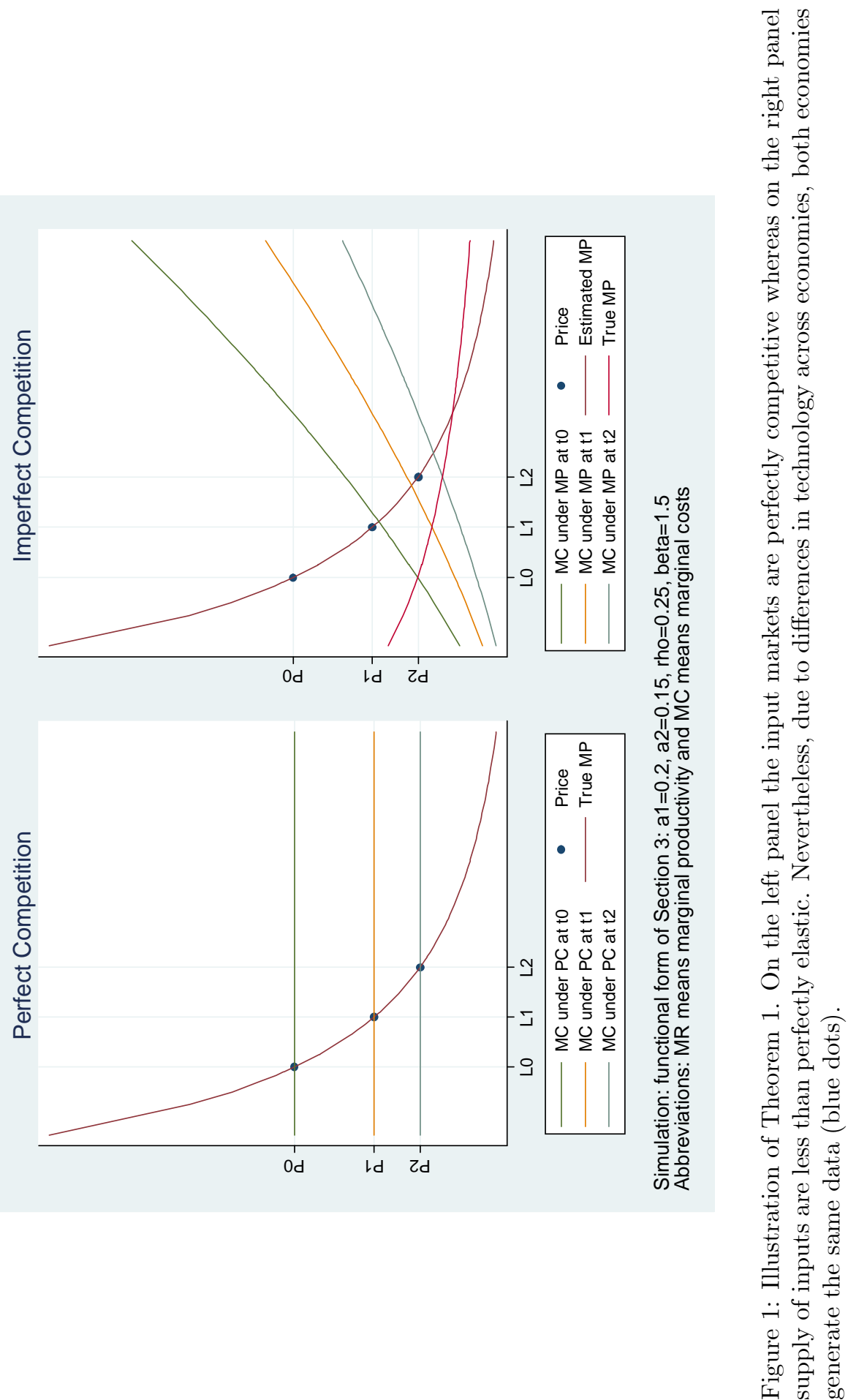


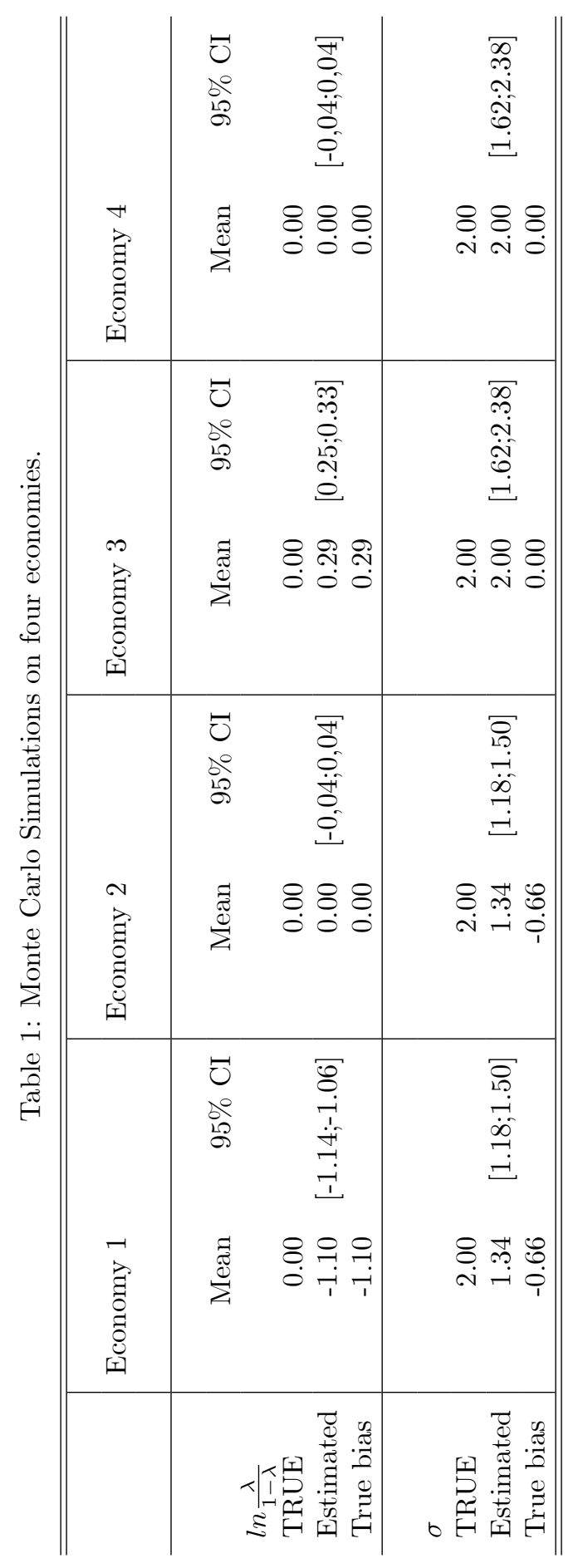

